Original Research Paper

\title{
Constrained Modified Genetic Algorithm for Optimizing RICE Climate Change Model Policy
}

\author{
Haitham Osman \\ Department of Chemical Engineering, King Khalid University, Abha 394, Saudi Arabia \\ Department of Chemical Engineering, University of Science and Technology, Omderman124, Sudan
}

\section{Article history}

Received: 15-12-2015

Revised: $30-01-2017$

Accepted: 30-03-2017

Email: haitham.osman@gmail.com

\begin{abstract}
The objective of this paper is to use evolutionary algorithm for policy making to help in decision support, the Regional Integrated ClimateEconomy (RICE) model for the dynamic climate change is used to optimize the tradeoff policy between abating of carbon dioxide emissions to reduce global climate change and in the other hand the resulting in economic damages. A Constrained Genetic Algorithms (CGAs) is modified to search for near global optimal solutions the by searching climate optimum control parameters that resulted in optimal $\mathrm{CO}_{2}$ abatement and temperature reduction with less economic damages. A Comparison study between optimizing the output of GAs with the standard solution revealed that GAs successfully found a better solution, in term of finding optimum values for the carbon prices that lead to more reduction in carbon emission comparing to solutions given by the model developer.
\end{abstract}

Keywords: Climate Change, RICE Model, Economic Policy, Green House Gases, Genetic Algorithm

\section{Introduction}

Green House Gases (GHGs) emissions are presently changing the energy balance of our planet, by trapping heat that would otherwise be radiated out into space. Our planet's average temperature is determined by a balance that is accumulated between the energy coming from the Sun and the energy reflected and emitted out into space.

Human activity caused changes to the greenhouse effect causing entrapment of more heat which drives global warming. Carbon dioxide $\mathrm{CO}_{2}$ is the gas most discussed. Which It is the main human-caused (anthropogenic) contributor, but it is not the only one (Richter, 2014).

Fading carbon dioxide emissions will definite reduces global climate change, but it is in other hand resulting in economic damages. This can be illustrated in Fig. 1, the upper circle shows increasing in the economic growth lead to rapidly rising emissions of $\mathrm{CO}_{2}$ into the atmosphere. The arrow then moves to the circle at the right, where the impacts of increasing $\mathrm{CO}_{2}$ concentrations lead to major changes in the Earth climate. On the lower circle, the changing climate produces impacts on human and natural systems.

In estimating impacts, the potential areas of concern have been divided by Nohadous into seven categories: 1 . Agriculture 2. Sea-level rise. 3. Other market sectors 4. Health 5. Nonmarket amenity impacts
Finally, the circle on the left shows the responses to the threat of climate change. The first and most simplified climate model taking into account the greenhouse effect was made in 1896 by Swedish chemist Svante Arrhenius, who went on to win the Nobel Prize in Chemistry in 1903. He calculated that reducing the $\mathrm{CO}_{2}$ in the atmosphere by half would lower the global temperature by about $5^{\circ} \mathrm{C}$, which is as much as it was actually reduced in the last ice age.

$\mathrm{He}$ also calculated that the temperature would increase by about $5^{\circ} \mathrm{C}$ if the $\mathrm{CO}_{2}$ in the atmosphere were doubled, not very different from today's far more sophisticated models (Nordhaus, 2014).

For at least the past 650,000 years the $\mathrm{CO}_{2}$ concentration levels have been below 300 ppmv at business-as-usual scenario BAU (no additional climate policy) and it is predicted to increase to $600 \mathrm{ppmv}$ by 2050 (Gowdy, 2008). If all available fossil fuels were burned $\mathrm{CO}_{2}$ levels could ultimately reach 2,000 ppmv (Kump, 2002). Scientists are uncertain and anticipate that the most likely scenario is the atmospheric $\mathrm{CO}_{2}$ will peak at 1,200 ppmv in the next century or at 1,400 ppmv in three centuries.

\section{Policy Making in Decision Support}

Global public policy issues are an extremely complex process that is affected by many factors, occur in rapidly changing environments characterized by uncertainty and involve conflicts among different interests. 


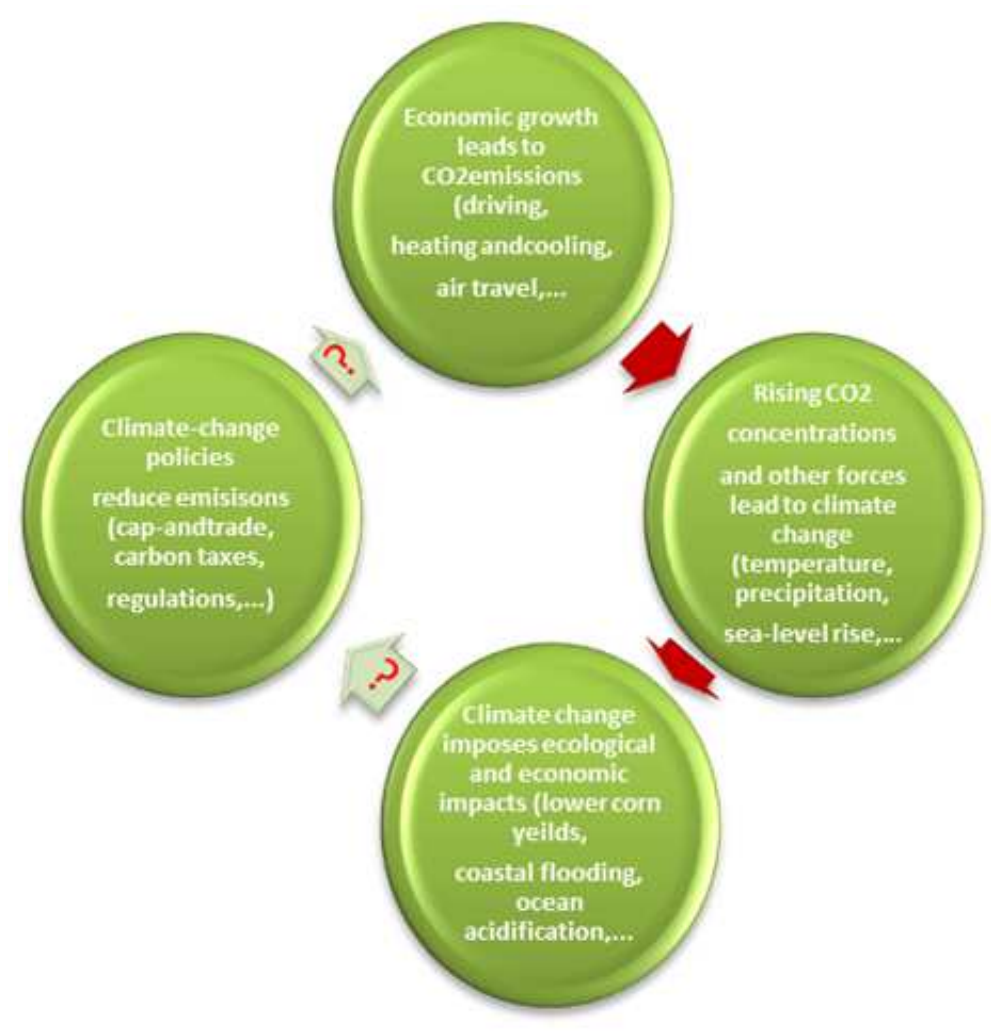

Fig. 1. The circular flow of global warming

Policymaking in the energy sector interprets the crucial aspect of energy production and energy efficiency that strongly affect economic development, sustainability and social acceptance. The energy production is heavily relying on burning fossil fuels, which produce carbon emissions that are responsible for climate change. Against this background, energy policy making is turning attention toward sustainable energy policies and low carbon economy, by possibly eliminating the direct use of fossil fuels, targeting renewable energy sources, promoting energy efficiency and strategically going toward the smart grid.

Computing techniques are important instruments for aiding governance and policy making: The literature reports attempts to use optimization, visual scenario evaluation agent-based simulation and opinion mining to support specific cases of this process. However, there is still a big gap for improvement.

Also, there are a number of technologies supporting decision making and optimization in the energy planning field (Gavanelli et al., 2010), namely Constraint Programming, Mixed Integer Linear Programming.

Gavanelli et al. $(2010 ; 2011)$ used of constraint reasoning techniques to increase the effectiveness of the process by enabling the policy maker to analyze various aspects and to play with parameters in order to obtain alternative solutions along with their environmental assessment also proposed a fuzzy model for the Strategic Environmental Assessment (SEA). It reported that: While being far more expressive than a traditional Constraint Logic Programming (CLP) approach, it is less usable within a regional planning decision support system. They evaluated a previous regional plan with two models and proposed the outputs to an environmental expert. Expert compared the two outputs and chose the CLP model as closest to a human-made assessment.

Given the amount of financial, human and environmental resources that are involved in regional plans, even a small improvement can have a huge effect.

Ruppert et al. (2015) presented a novel approach to tackle the challenges of the policy paradox by information visualization technologies of the policy analysis field. They used visual decision support systems as the means to bridge gaps in policy analysis.

\section{DICE and RICE Model for the Climate Change}

The Dynamic Integrated Climate-Economy (DICE) model was first presented in its modern form by (Nordhaus, 1994; 1993), who described the new, fully dynamic Ramsey-type optimal growth structure of the model and the optimal time path of emission reductions and associated carbon taxes that emerged from it.

Nordhaus described the Dice model as an integrator and an end-to-end fashion the economics, carbon cycle, 
climate science and impacts in a highly aggregated model that allow[s] a weighing of the costs and benefits of taking steps to slow greenhouse warming.

DICE and RICE models couple a Ramsey-CassKoopmans exogenous growth economy to a model of the climate system. The economy produces emissions that accumulate in the atmosphere, change the radiative forcing in the atmosphere and warm the planet's surface. This warming feeds back into economic production and consumption.

The RICE and DICE models used an empirical approach to estimating the $\mathrm{CO}_{2}$ flows, estimating the parameters of the emissions concentrations equation built from previous data on emissions and concentrations. The main purpose of the economic and environmental policies is to improve the living standards or consumption of people now and in the future, it can view climate change in the framework of economic growth theory. It also can view concentrations of Green House Gases (GHGs) as "negative natural capital" and emissions reductions as lowering the quantity of that negative capital. Emissions reductions lower consumption today by preventing economically harmful climate change but, on the other, increase consumption possibilities in the future (Nordhaus, 2010).

The models divide the global world into 12 regions. Some are large countries such as the United States or China; others are large multi-country regions such as the European Union or Latin America. Each region is parameterized with a well-defined set of preferences, represented by a social welfare function and to optimize its consumption, GHG policies and investment over time. The social welfare function is increasing in the per capita consumption of each generation, with diminishing the marginal utility of consumption (Nordhaus, 1993).

The climate module is unchanged from the original DICE and RICE models. In term of both model contains a traditional economic sector like that found in many economic models and geophysical relationships designed for climate-change modeling. The mathematical representation of this assumption is that policies are chosen to maximize a social welfare function, $\mathrm{W}$, which is the discounted sum of the population-weighted utility of per capita consumption:

$W=\sum_{t=0}^{T}[U[c(t), t, T(t)] R(t)]$

The notation is that $c(t)$ is per capita consumption, $L(t)$ is population as well as labor inputs and $R(t)$ is the discount factor which is defined by:

$R(t)=(1+\rho)^{-t}$

The Dynamic growth model incorporates a simple feedback mechanism between economic activity and climate change. The objective in the model is to maximize social well-being with a particular set of decisions about investment and $\mathrm{CO}_{2}$ abatement over time. Wellbeing is represented in the model by a flow of utility $\mathrm{U}$; defined as the product of the logarithm of per capita consumption per year; and the exogenously given population L:

$U=L(t) c(t)$

The objective is to identify a policy that maximizes the discounted sum of utility $U^{*}$ :

$\operatorname{Max} \sum_{t=0}^{T}\left[(1+\rho)^{-t} L_{t} \log \left(\frac{c(t)}{L(t)}\right)\right]$

Welfare is maximized subject to a number of Economic, technological and climatic constraints.

A list of the RICE model important equation is provided in the Appendix A, the model itself is available in an Excel version at the author's webpage at http://www.econ.yale.edu/ nordhaus/homepage/RICEm odels.htm.

\section{RICE Climate Change Model and Health Impact}

The potential damages from climate change are divided into seven categories: Agriculture, sea level rise, other market sectors, human health, nonmarket amenity impacts, human settlements and ecosystems and catastrophes. A full recounting of the derivation of the damage functions in all categories is drawn heavily from (Keller et al., 2004) which summarized below, Many Studies talked about the Climate change impacts on human health and indicate the potential for the spread of tropical diseases to subtropical or temperate regions if warming proceeds more rapidly than improvements in health care keep pace.

They mention that among the major tropical diseases that may increase their range are malaria, dengue and yellow fever (Gavanelli et al., 2010). Impacts may also occur through the interaction of air and water pollution with higher temperature and more frequent river floods.

Unfortunately, there are currently no comprehensive studies of the health impacts of global warming. Most studies also ignore the impacts of extremes of cold (which would be reduced) and focus primarily on extremes of heat (which would be increased). In the absence of systematic estimates of health impacts, Nordhaus relied on estimates based on the current prevalence of climate-related diseases. The most comprehensive study of the global incidence of disease provides estimates of Years of Life Lost (YLLs) and DisabilityAdjusted Lives Lost (DALYs) prepared by Murray and Lopez (1997). Based on the data in that study, they have classified diseases into climate related and non-climate related. The former include malaria, along with a broad group of tropical diseases, dengue fever and pollution. 
Murray and Lopez group sub-regions into eight broad regions, which correspond reasonably well with the grouping in RICE model.

\section{Optimization of the Model}

The optimization of climate change model is a nontrivial task, that introduces non-smooth gradients and local optima, which limit the modified Newton algorithm and other methods based on explicit or implicit derivative information. The numerical problems introduced by the local optima are typically addressed by the choice of a global optimization method such as simulated annealing or a genetic algorithm (Pierre, 2012; Keller et al., 2004).

To overcome the computational problems caused by the climate change problem, global optimization algorithm specifically genetic algorithm method is used, which does not rely on gradient Information is used and modified to find multiple sub-optimal solutions Instead of single Global optimum solution.

\section{Constrained Genetic Algorithm}

The genetic algorithm method has been proven to be successful in complex optimization problems such as wire routing, scheduling, adaptive control, game playing, cognitive modeling, transportation problems, traveling salesman problems, optimal control problems and database query optimization. Nordhaus optimized the Excel model, by using proprietary software called "Risk Solver Platform," developed by Frontline Solvers. His Excel sheet ships with optimized numbers, but Risk Solver (or GAMS, or another solver) is required for doing new optimizations, it can be used to alter the model. The optimization proprietary software used Monte Carlo simulation trials in parallel with algebraically formulas analysis, with a computation for function gradient and curvature.

The genetic algorithm selects the best solutions among a population of evolving candidate by using the fitness function to evaluate each solution to decide whether it will contribute to the next generation of solutions. With operations analogous to gene crossover and mutation and then reproduction, the algorithm creates a new population of candidate solutions (Goldberg, 1989). The most important genetic operators are the initialization (a different set of populations are used each run), crossover, mutation, selection and termination) Fig. 2 and 4.

Unfortunately, there is no guarantee that the algorithm can find the global optima without sticking in the local optima.

However, the method is modified as follows to test at least approaching near global optimum solutions: Different set of population member are used each run, increasing the number of iterations, increasing the mutation rate in the evolutionary algorithm and graphically inspecting the utility function along selected sections of the solution space, as it can be seen in Fig. 3 .

The following is the general specifications of SGAs are applied to optimize RICE Model carbon price.

Chromosome encoding: The control decision variables are encoded using the binary system; the $\mathrm{CO}_{2}$ pricing encoded as 16 bit in chromosome length.

Fitness assignment: After the objective function is calculated the fitness function is scaled in the range then the Population are ranked related to their fitness value.

Genetic operators: The single point crossover with a probability of $\mathrm{Pc}=0.95$ is chosen as it proved to work in the most difficult optimization problem, the single point mutation with $\mathrm{Pm}=0.01$ is used and the size population is 100 individuals.

Objective function: The task of the optimal policy is to balance the costs and benefits of $\mathrm{CO}_{2}$ abatement the welfare function in Equation 3 is to be maximized.

Constraints enforce the policy of reducing maximum increase of temperature to $2^{\circ} \mathrm{C}$

The control variables are used as the price of the $\mathrm{CO}_{2}$ up to the year 2055, to examine the impact of changing the price in the period in climate change up to the year 2055.

The algorithm is run in Intel core i5 and 4GB ram, with 200 generation stopping criteria, consumed about $15 \mathrm{~min}$ and $23 \mathrm{sec}$. The resulted solutions are plotted.

Dataset available in reference 'Economic aspects of global warming in a post-Copenhagen environment' (Nordhaus, 2010).

The objective is to maximize the discount sum of individuals utility $\mathrm{U}$ as defined in the $\mathrm{A}$.

The decision variables are the $\mathrm{CO}_{2}$ abatement over the time, the reported period is from the year 1995 until 2155, a shorter time horizon of 50 years is used to study the impact of using the stochastic method on the policy, this resulted in 10 decision variables. Researchers reported that even for a stabilization of emissions within the next 7 years, the atmospheric carbon content will need about 400 years to reach its steady state. The relations between the objective function and the decision variables is very nonlinear.

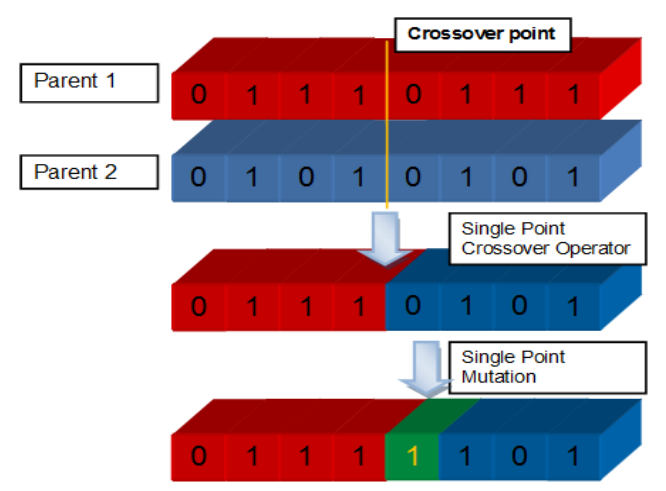

Fig. 2. Representation for the chromosome encoding, genetic operators 
The policy is to reduce the ppm concentration; Researchers (Richter, 2014) reported that the truly optimal Policies should keep the $\mathrm{CO}_{2}$ peak much closer to the deterministic policy. The optimal mean peakCO $\mathrm{CO}_{2}$ concentration is only $12 \mathrm{ppm}$ higher under uncertainty over the damage coefficient.

Dataset available in reference 'Economic aspects of global warming in a post-Copenhagen environment' (Nordhaus, 2010).

\section{Results and Discussion}

This study differs from previous studies of optimal $\mathrm{CO}_{2}$ abatement mostly in the representation of the climate optimizing control parameters and the effects of parameter uncertainty on optimal $\mathrm{CO}_{2}$ abatement and temperature reduction. Table 1 . Shows that Carbon prices in the different runs compared with the original Nordhaus results Fig. 3 shows temperature profile presenting slight reduction obtained by the GA. In Fig. 4 the carbon total emissions are oscillating in comparison with the optimum values obtained by Nordhaus, on the other hand, Fig. 5 shows that the percentage of climate damage has been reduced when using the GAs optimizer of carbon pricing in comparison to the Nordhaus optimized results. Figure 6 and 7 shows the maximum concentration is slightly less than 600 ppmv for GA but it is equal to $600 \mathrm{pmv}$ for the Nordhaus results.

\section{Comparison to Previous Studies}

This study differs from previous studies of optimal $\mathrm{CO}_{2}$ abatement mostly in the representation of the climate optimizing control parameters and the effects of parameter uncertainty on optimal $\mathrm{CO}_{2}$ abatement and temperature reduction. Nordhaus used excel solver to optimize Carbon price for the 50 years. Constrained GA is compared with excel solver revealed that better abatement and temperature reduction can be achieved see Fig. 8 and 9, but it is oscillatory in the Emissions control rate for all countries.

\{Store the best solution;

Obtain the neighbor solutions for the best solution;

Compare the best solution and best neighbor solution;\}

Fig. 3. Modified routine for finding optimum solution

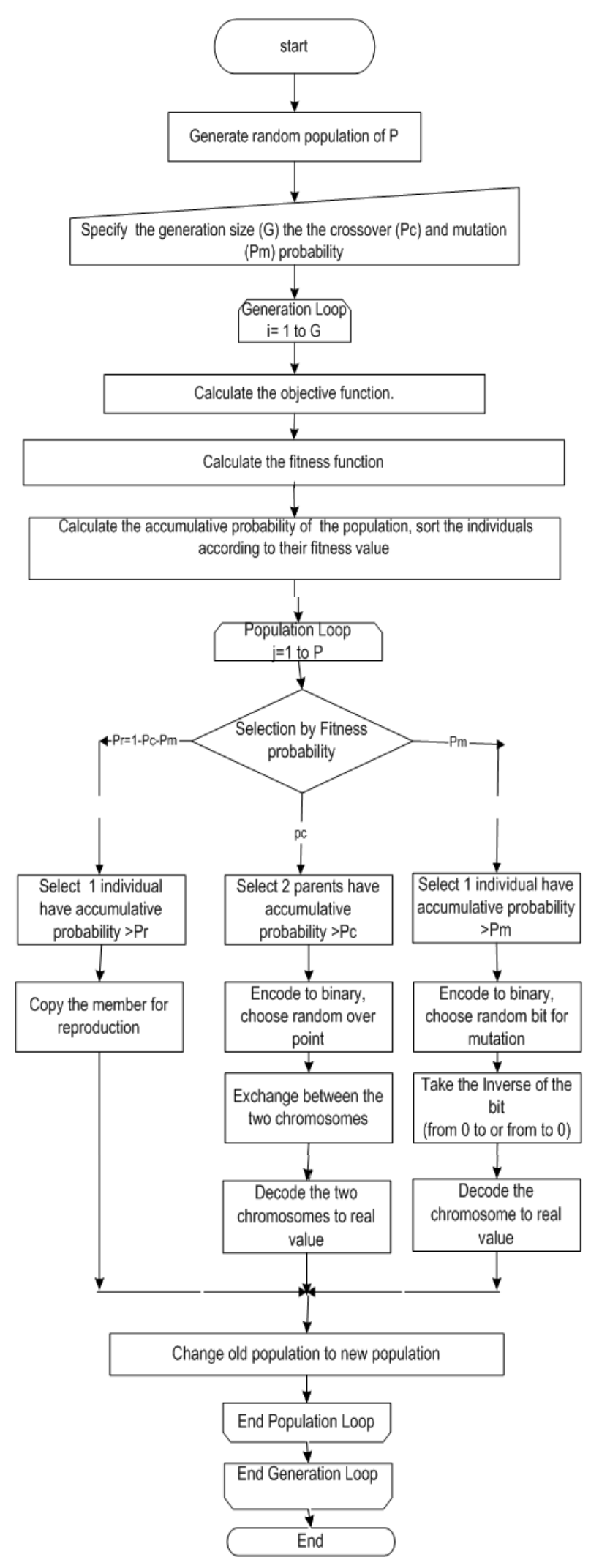

Fig. 4. Simple genetic algorithm chart 
Haitham Osman / American Journal of Applied Sciences 2017, 14 (10): 945.954 DOI: 10.3844/ajassp.2017.945.954

Table 1. Carbon prices in the different runs

Carbon prices per ton 2005

GA optimal carbon cost

0.0

2015

41

2025

160

2035

30

Nordhaus optimal carbon cost*

0.0

37.9

65.5

89.5

2055

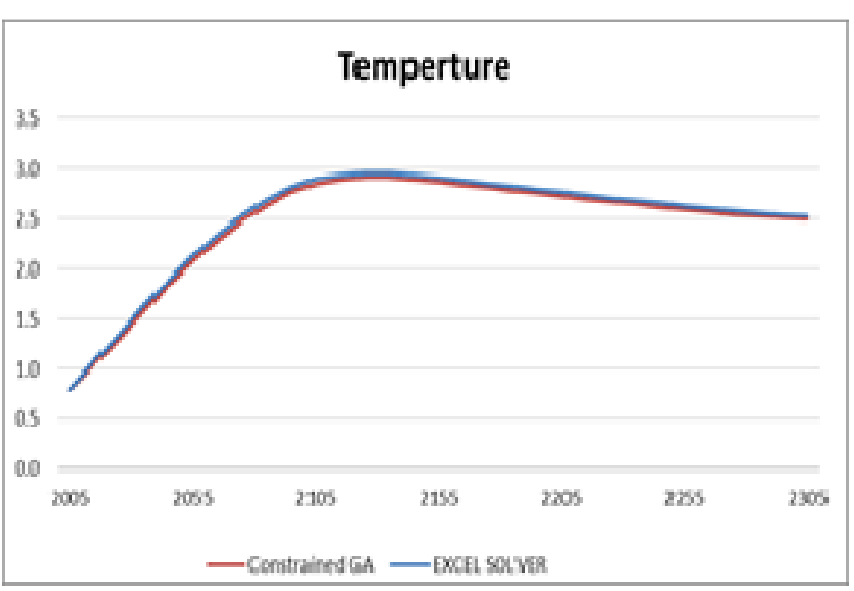

Fig. 5. Temperature profile

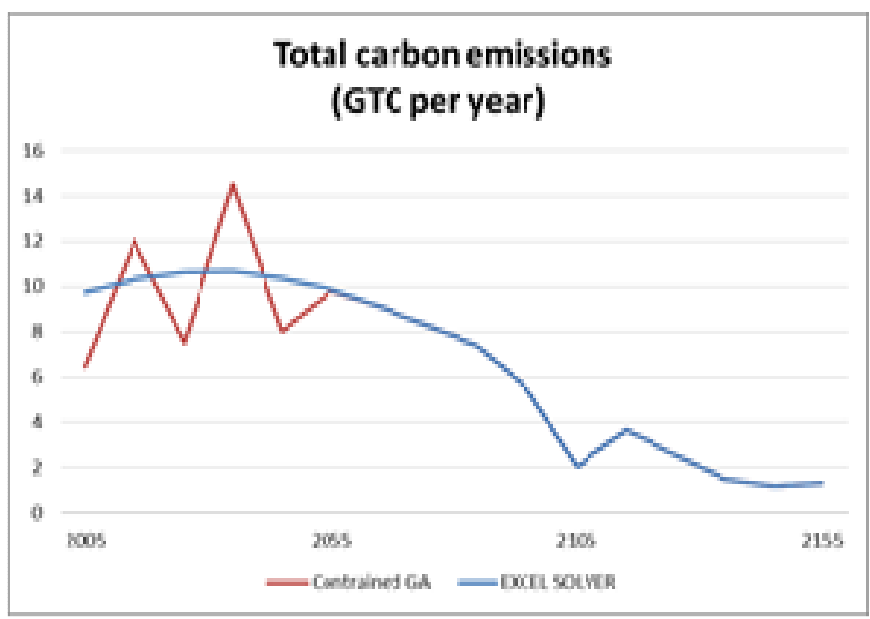

Fig. 6. Total carbon emissions

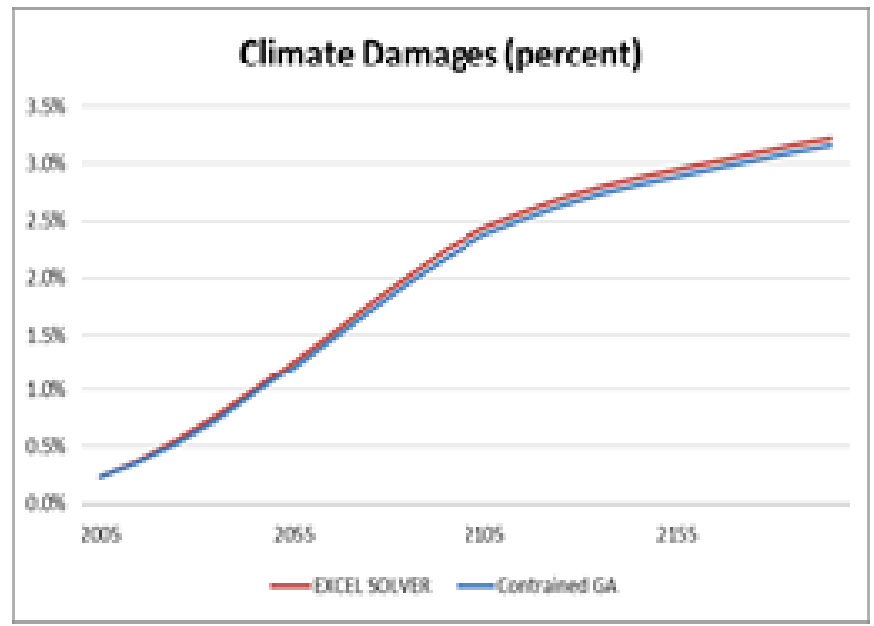

Fig. 7. Percentage of climate change 


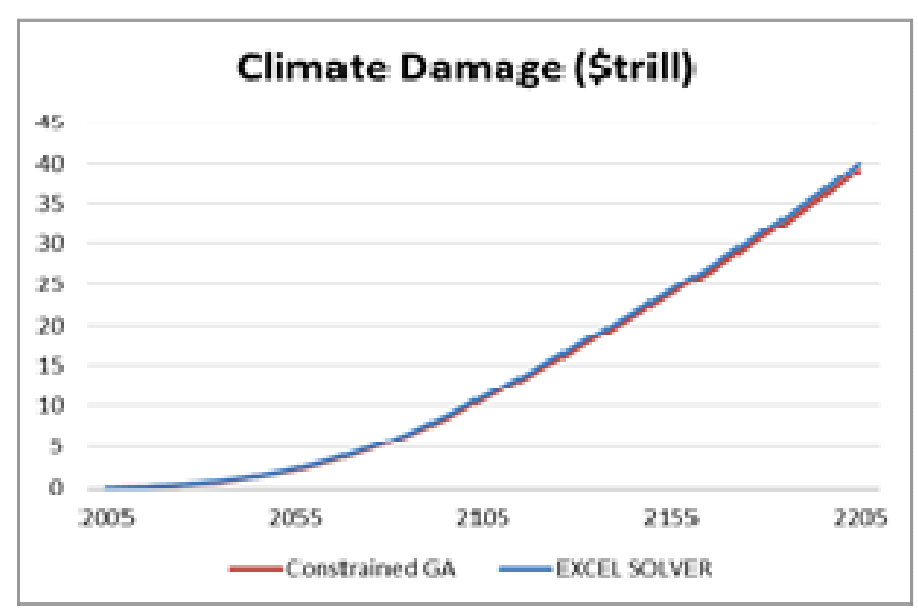

Fig. 8. Price of climate damage in trillion

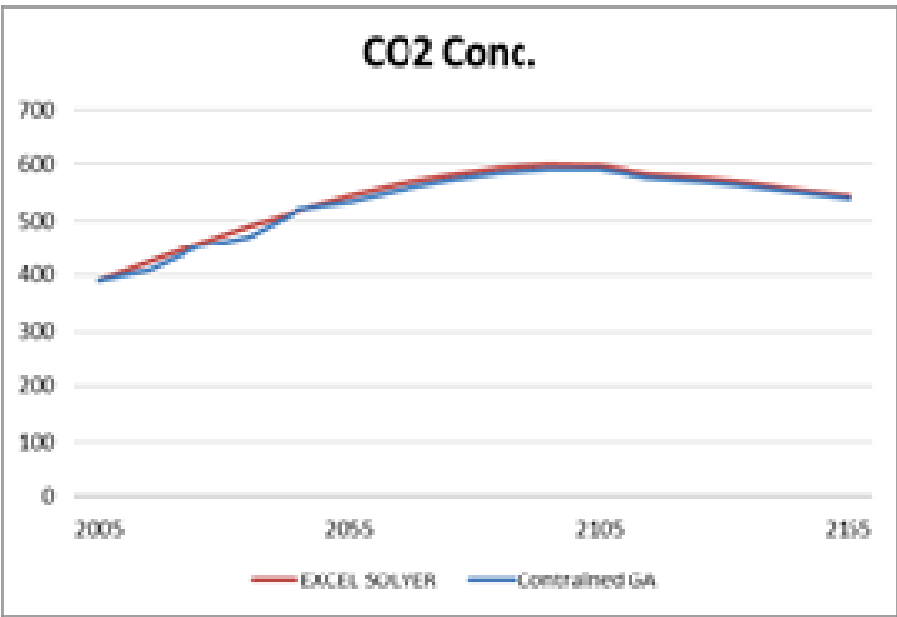

Fig. 9. $\mathrm{CO}_{2}$ concentration

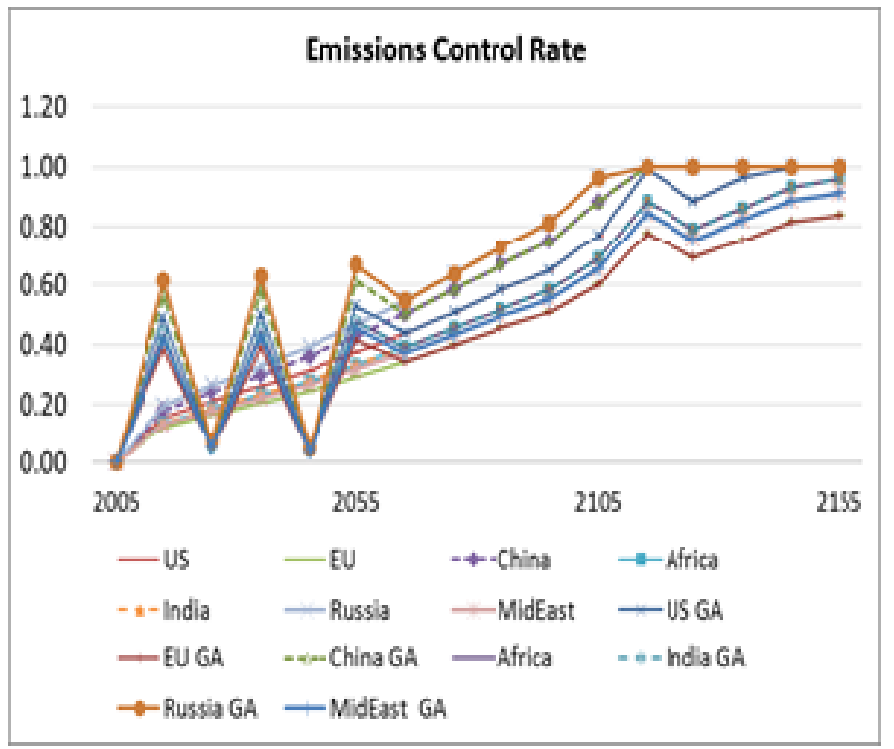

Fig. 10. Emissions control rate for selected countries 


\section{Conclusion}

Results presented in this article were successfully attained by optimizing carbon price policy by taking into account the Welfare with minimum environmental damage using constrained GAs. The algorithm has succeeded in optimizing the model, thus outperformed all previous results, the temperature is kept at $0.2^{\circ} \mathrm{C}$ less than comparing to Nordhaus previous results.

Due to the instability of pricing during the 5 periods, the total carbon emission oscillates. Such oscillation can lead to huge economic problems not to mention $\mathrm{CO}_{2}$ concentration oscillation accordingly.

\section{Further Recommendations}

With a given global environment under a strict climate policy, economic changes cannot predict with certainty, but they can be guided and controlled within boundaries. As it can be noted that in Fig. 8 the oscillatory in Emissions control rate caused by the policy change in the carbon pricing if a severe climate policy turns out to create too high economic costs and too much instability, the policy should be modified or adapted. However, governments will be unable to avoid extreme impacts on the world economy and economic policy will have a very hard time stabilizing economic responses to severe climate change.

\section{Ethics}

This article is original and to the best knowledge of the author has not been published before. The author confirm that there are no ethical issues involved.

\section{References}

Gavanelli, M., F. Riguzzi, M. Milano and P. Cagnoli, 2010. Logic-based decision support for strategic environmental assessment. Theory Practice Logic Programm., 10: 643-658.

DOI: $10.1017 / \mathrm{S} 1471068410000335$

Gavanelli, M., F. Riguzzi, M. Milano, D. Sottara and A. Cangini et al., 2011. An Application of Fuzzy Logic to Strategic Environmental Assessment. In AI*IA 2011: Artificial Intelligence Around Man and Beyond, Pirrone, R. and F. Sorbello (Eds.), Springer, Berlin, ISBN-10: 3642239544, pp: 324-335.

Goldberg, D.E., 1989. Genetic algorithms in search, optimization and machine learning.

Gowdy, J.M., 2008. Behavioral economics and climate change policy. J. Econom. Behavior Organizat., 68: 632-644. DOI: 10.1016/j.jebo.2008.06.011

Keller, K., B.M. Bolker and D.F. Bradford, 2004. Uncertain climate thresholds and optimal economic growth. J. Environ. Econom. Manage., 48: 723-741. DOI: $10.1016 /$ j.jeem.2003.10.003
Kump, L.R., 2002. Reducing uncertainty about carbon dioxide as a climate driver. Nature, 419: 188-190. PMID: 12226672

Murray, C.J. and A.D. Lopez, 1997. Alternative projections of mortality and disability by cause 1990-2020: Global Burden of Disease Study. Lancet, 349: 1498-1504. DOI: 10.1016/S0140-6736(96)07492-2

Nordhaus, W.D., 1993. Rolling the 'DICE': An optimal transition path for controlling greenhouse gases. Resource Energy Econom., 15: 27-50. DOI: 10.1016/0928-7655(93)90017-O

Nordhaus, W.D., 1994. Managing the Global Commons: The Economics of Climate Change. 1st Edn., MIT Press, Cambridge, ISBN-10: 0262140551, pp: 213.

Nordhaus, W.D., 2010. Economic aspects of global warming in a post-Copenhagen environment. Proc. National Acad. Sci., 107: 11721-11726.

Nordhaus, W.D., 2014. A Question of Balance: Weighing the Options on Global Warming Policies. 1st Edn., Yale University Press, New Haven, ISBN-10: 0300209398, pp: 234.

Pierre, D.A., 2012. Optimization Theory with Applications. 1st Edn., Courier Corporation, Dover Publications, ISBN-10: 0486136957, pp: 640.

Richter, B., 2014. Beyond Smoke and Mirrors: Climate Change and Energy in the 21st Century. 1st Edn., Cambridge University Press, ISBN-10: 1107673720, pp: 379.

Ruppert, T., J. Dambruch, M. Krämer and T. Balke et al., 2015. Visual Decision Support for Policy Making: Advancing Policy Analysis with Visualization. In: Policy Practice and Digital Science: Integrating Complex Systems, Social Simulation and Public Administration in Policy Research, Janssen, M., M.A. Wimmer and A. Deljoo (Eds.), Springer, Cham, ISBN-10: 3319127845, pp: 321-353.

\section{Appendix}

\section{RICE 2010 Model Major Equations}

The following lists the major equations in the RICE-2010 model developed by Nordhaus. Only important equations are considered. Note that the subscript $k$ represents regions.

(A1) Welfare:

$$
W=\sum_{k=1}^{12} \sum_{t=1}^{T \max }\left(\phi_{k t} u\left[c^{k}(t), L^{k}(t)\right] R(t)\right)
$$

(A2) Discount factor:

$$
R(t)=(1+p)^{-t}
$$

(A3) Utility function:

$$
U\left[c^{k}(t), L^{k}(t)\right]=L^{k}(t)\left[c^{k}(t)^{1-\alpha} /(1-\alpha)\right]
$$


(A4) Output before damages and abatement:

$$
Y^{k}(t)=A^{k}(t) K^{k}(t)^{\gamma} L^{k}(t)^{1-\gamma}
$$

(A5) Abatement cost as a fraction of output:

$$
\Lambda^{k}(t)=Y^{k}(t) \theta_{I}(t) \mu^{k}(t)^{\theta_{2}}
$$

(A6) Climate damages as a fraction of output:

$$
\begin{aligned}
& \Omega^{k}(t)=g^{k}\left[T(t), S L R(t), M_{A T}(t)\right] \\
& /\left(1+g^{k}\left[T(t), S L R(t), M_{A T}(t)\right]\right)
\end{aligned}
$$

(A7) Output after damages and abatement:

$$
\left.Q^{k}(t)=\Omega^{k}(t) f 1-\Lambda^{k}(t)\right] Y^{k}(t)
$$

(A8) Composition of output

$$
Q^{k}(t)=C^{k}(t)+I^{k}(t)
$$

(A9) Per capita consumption

$$
c^{k}(t)=C^{k}(t) / L^{k}(t)
$$

(A10) Law of motion of capital stock:

$$
K^{k}(t)=I^{k}(t)-\delta_{K} K^{k}(t-1)
$$

(All) Industrial emissions:

$$
\left.E_{\text {Ind }}^{k}(t)=\sigma^{k}(t) f 1-\mu^{k}(t)\right] Y^{k}(t)
$$

(A12) Carbon fuel limitations:

$$
\text { CCum } \geq \sum_{t=1}^{T \max }\left[\sum_{k=1}^{12} E_{l n d}^{k}(t)\right]
$$

(A13) Total carbon emissions:

$$
E^{k}(t)=E_{\text {lnd }}^{k}(t)+E_{\text {Land }}^{k}(t)
$$

(A14) Dynamics of atmospheric carbon concentrations:

$$
M_{A T}(t)=E(t)+\varnothing_{11} M_{A T}(t-1)+\varnothing_{21} M_{u P}(t-1)
$$

(A15) Dynamics of carbon concentrations in the biosphere and upper oceans:

$$
M_{U P}(t)=\varnothing_{12} M_{A T}(t-1)+\varnothing_{22} M_{U P}(t-1)+\varnothing_{32} M_{L O}(t-1)
$$

(A16) Dynamics of carbon concentrations lower oceans:

$$
M_{L O}(t)=\varnothing_{23} M_{U P}(t-1)+\varnothing_{33} M_{L O}(t-1)
$$

(A17) Radiative forcings:

$$
F(t)=\eta\left\{\log _{2} f M_{A T}(t) / M_{A T}(1750) J\right\}+F_{E X}(t)
$$

(A18) Global mean surface temperature:

$$
\begin{aligned}
& T_{A T}(t)=T_{A T}(t-1)+\xi_{1}\{F(t) \\
& -\xi_{2} T_{A T}(t-1)-\xi_{3}\left[T_{A T}(t-1)-T_{L O}(t-1) J\right\}
\end{aligned}
$$

(A19) Temperature lower oceans:

$$
T_{L O}(t)=T_{L O}(t-1)+\xi_{4}\left\{T_{A T}(t-1)-T_{L O}(t-1) J\right\}
$$

(A20) Sea level rise (thermal expansion, glaciers, ice sheets):

$$
\begin{aligned}
& \operatorname{SLR}(t)=\operatorname{SLR}(t-1) \\
& +\left[\sum_{j=1}^{5} \pi_{1, j}+\pi_{2, j} T_{A T}(t-1)+\pi_{2, j}\left[T_{A T}(t-1)-\bar{T}\right]\right]
\end{aligned}
$$

Variable Definitions and Units

$A(t) \quad=$ Total factor productivity (productivity units)

$* e(t) \quad=$ Per capita consumption of goods and services (2005 U.S. dollars per person)

${ }^{*} C(t) \quad=$ Consumption of goods and services (trillions of 2005 U.S. dollars)

$* D(t) \quad=$ Damages from climate change (trillions of 2005 U.S. dollars)

$E_{\text {land }}(t)=$ Emissions of carbon from land use (billions of metric tons $C$ per period)

$* E_{1 n d}(f) \quad=$ Industrial carbon emissions (billion metric tons $C$ per period)

$* \mathrm{E}(\mathrm{t}) \quad=$ Total carbon emissions (billion metric tons $C$ per period)

$* F(t), F_{E X}(t) \quad=$ Total and exogenous radiative forcing

$* g^{k}[T(t)$,

$\left.\operatorname{SLR}(t), M_{A T}(t)\right]=$ Damage function

$* I(t) \quad=$ Investment (trillions of 2005 U.S. dollars)

$* K(\mathrm{t})=$ Capital stock (trillions of 2005 U.S. dollars)

$L(t) \quad=$ Population and proportional to labor inputs (millions)

$* \Lambda(t) \quad=$ Abatement cost as fraction of output

$* M_{A T}(t)$

$M_{U P}(t), M_{L O}(t)=$ Mass of carbon in reservoir for atmosphere, upper oceans and lower oceans (billions of metric tons $\mathrm{C}$, beginning of period)

$* \mu(t) \quad=$ Emissions-control rate (fraction of uncontrolled emissions) 


\begin{tabular}{|c|c|c|c|}
\hline$\sigma(t)$ & $\begin{aligned}= & \text { Ratio of uncontrolled industrial } \\
& \text { emissions to output (metric tons } C \text { per }\end{aligned}$ & $=$ & $\begin{aligned}= & \text { Rate of depreciation of capital (per } \\
& \text { period) }\end{aligned}$ \\
\hline$* \Omega(t)$ & $\begin{aligned} & \text { output in } 2005 \text { prices) } \\
&= \text { Damage function (climate damages as } \\
& \text { fraction of regional output) }\end{aligned}$ & $\eta \quad=$ & $\begin{aligned}= & \text { Temperature-forcing parameter }\left({ }^{\circ} \mathrm{C} \text { per }\right. \\
& \text { watts per meter squared })\end{aligned}$ \\
\hline$* \Lambda(t)$ & $\begin{aligned}= & \text { Abatement cost function (abatement } \\
& \text { costs as fraction of regional output) }\end{aligned}$ & \multicolumn{2}{|c|}{$\begin{array}{l}\emptyset_{11}, \emptyset_{21}, \emptyset_{22}, \\
\emptyset_{32}, \emptyset_{12}, \emptyset_{33}, \emptyset_{23}=\begin{array}{l}\text { Parameters of the carbon cycle (flows } \\
\text { per period) }\end{array}\end{array}$} \\
\hline$* Q(t)$ & $\begin{array}{l}=\text { Output of goods and services, net of } \\
\text { abatement and damages (trillions of } \\
2005 \text { U.S. international dollars) }\end{array}$ & $\xi_{1}, \xi_{2}, \xi_{3}, \xi_{4}=$ & $\begin{aligned} & \text { per period) } \\
= & \text { Parameters of climate equations (flows } \\
& \text { per period) }\end{aligned}$ \\
\hline$S L R(t)$ & $=$ Sea level rise (relative to 1990 ), meters & $\psi_{1}, \psi_{2}$ & $=$ Parameters of damage function \\
\hline$t$ & $\begin{array}{l}=\text { Time }(\text { decades from } 2001-2010,2011- \\
2020, \ldots)\end{array}$ & $p$ & $\begin{aligned}= & \text { Pure rate of social time preference } \\
& \text { (per year) }\end{aligned}$ \\
\hline$* \tau_{A T}(\mathrm{t}), T_{L O}(t)$ & $\begin{array}{l}=\text { Global mean surface temperature, } \\
\text { temperature upper oceans, temperature }\end{array}$ & $R(t)$ & $\begin{aligned}= & \text { Social time preference discount factor } \\
& (\text { per time period) }\end{aligned}$ \\
\hline$* U[c(t), L(t)]$ & $\begin{aligned} & \text { lower oceans }\left({ }^{\circ} \mathrm{C} \text { from } 1900\right) \\
&= \text { Instantaneous utility function (utility } \\
& \text { per period) }\end{aligned}$ & $\operatorname{Tmax}$ & $\begin{aligned}= & \text { Length of estimate period for model }(60 \\
& \text { periods }=600 \text { years for most variables })\end{aligned}$ \\
\hline$* W$ & $\begin{array}{l}=\text { Objective function in present value of } \\
\text { utility (utility units) }\end{array}$ & $\bar{T}(t)$ & $\begin{aligned}= & \text { Threshold temperatures for ice sheets } \\
& \text { in SLR equation }\left({ }^{\circ} \mathrm{C}\right)\end{aligned}$ \\
\hline$* Y(t)$ & $\begin{array}{l}=\text { Output of goods and services, gross of } \\
\text { abatement and damages (trillions of }\end{array}$ & $\theta_{1}(t), \theta_{2}$ & $\begin{aligned}= & \text { Parameters of the abatement cost } \\
& \text { function }\end{aligned}$ \\
\hline & 2005 U.S. dollars) & $\phi_{k f}$ & $\begin{aligned}= & \text { Negishi parameters of the social } \\
& \text { welfare function }\end{aligned}$ \\
\hline Parameters & & Time steps. & The current model runs on10-year \\
\hline$\alpha$ & $\begin{aligned} &= \text { Elasticity of marginal utility of } \\
& \text { consumption (pure number) }\end{aligned}$ & & \\
\hline CCum & $\begin{aligned}= & \text { Maximum consumption of fossil fuels } \\
& \text { (billions metric tons carbon) }\end{aligned}$ & & \\
\hline$\gamma$ & $\begin{aligned}= & \text { Elasticity of output with respect to } \\
& \text { capital (pure number) }\end{aligned}$ & & \\
\hline
\end{tabular}

